\title{
Foreign Language Students' Voices on Blended Learning and Fully Online Classes during the COVID-19 Pandemic
}

\author{
Daniel Ginting ${ }^{1}$, Fahmi $^{2}$, Yusawinur Barella ${ }^{3}$, Andini Linarsih ${ }^{3}, \&$ Beny Hamdani ${ }^{4}$ \\ ${ }^{1}$ Universitas Ma Chung, Indonesia \\ ${ }^{2}$ Universitas Ahmad Dahlan, Indonesia \\ ${ }^{3}$ Universitas Tanjungpura, Indonesia \\ ${ }^{4}$ University of Islam Zainul Hasan, Indonesia \\ Correspondence: Daniel Ginting, Universitas Ma Chung, Indonesia.
}

Received: June 10, 2021

doi:10.5430/wjel.v11n2p62
Accepted: July 26, $2021 \quad$ Online Published: August 4, 2021

URL: https://doi.org/10.5430/wjel.v11n2p62

\begin{abstract}
Due to the restrictions of direct interactions during the pandemic, educational practices have massively and simultaneously shifted to remote teaching. Remote teaching is to some extent often viewed as an ineffective means of instructional delivery. It lacks the kind of interactions between teachers and students that are primarily found in traditional classrooms. In addition to ubiquitous technical hindrances, many educators find students' learning progress hard to monitor in remote teaching. The obstacles in remote teaching have prompted the government and educators to explore the possibilities of holding face-to-face meetings in a blended learning format amid the pandemic. This paper is aimed to present a sketch of students' perceptions of the possibilities of combining face-to-face classes with online learning during a pandemic. Using online surveys for data gathering and descriptive statistics for data analysis, this study found that students' perception of current emergencies influences their preferred mode of instructional delivery. The students appear to be much more tolerant of numerous hindrances in remote teaching than the potential risks of COVID-19 transmission. Most students in this study preferred fully online learning to blended learning. For them, health is the top priority.
\end{abstract}

Keywords: remote teaching, online learning, COVID-19, pandemic, blended learning

\section{Introduction}

Education practitioners worldwide are facing challenges to make the best decisions amid the COVID-19 pandemic (Daniel, 2020). The first option was to shut down offline teaching and ask students to learn by themselves at home (Dhawan, 2020). The second option was to teach face-to-face in the classroom under certain conditions, such as limiting the number of the students in each class adhering to physical distancing, wearing masks, and washing hands. The third option was to integrate online learning (Horzum, 2017; Anderson, 2008) into their teaching practices and make use of learning management systems (Elhawwa, 2017) such as Google Classroom and Canvas (Yundayani et al., 2019). In most countries, education has now shifted to remote teaching during the pandemic (Handarini \& Wulandari, 2020; Rosyada \& Sundari, 2021). Making the best decisions for education during a pandemic is not always easy, and decision-makers need to consider numerous issues such as people's digital literacy skills, their technical capabilities to access digital materials, and internet support. Above all, health is also one of the top priorities that cannot be neglected.

The Indonesian government issued several policies to deal with the current emergency. For example, on August 7 , 2020, the government issued a revised Joint Decree of Four Ministers. At that time, schools were given the flexibility to choose their curriculum to suit their needs and conditions. In March, the national examination was canceled. In addition to school examinations, a portfolio of student reports and achievement were used to determine graduation. Moreover, from March to April 2020, the Ministry of Education and Culture provided a free quota, reallocating a billion rupiahs to support public facilities and education during the pandemic. To enhance learning from home, the government mandated the national television station to broadcast learning materials nationally. At the same time, schools were also given the privilege of managing the government's financial aid to pay teacher fees, school facilities, and other relevant costs during the emergency. From May to 
June 2020, the Ministry of Education and Culture offered single tuition assistance for four hundred and ten thousand students whose families were affected by the pandemic. The Ministry of Education and Culture also provided internet quota subsidies for students, teachers, students, and lecturers for four months from September to December 2020: $35 \mathrm{~GB} /$ month for students, $42 \mathrm{~GB} /$ month for teachers, and $50 \mathrm{~GB} /$ month for college students and lecturers (Sulisworo et al., 2020). These show how serious the government has been in handling problems caused by the pandemic. While inequality in access to technology is quite massive in some regions in Indonesia, the Indonesian government has taken concrete actions to help ease the burden on the society, including the residents living in remote areas.

Remote teaching, which has been running for more than a year and a half at the time of writing, has inevitably caused technical and psychosocial problems. While the government has issued severe measures to combat COVID-19, such as providing vaccinations, the Minister of Education has let the local governments and schools make decisions about meeting face-to-face in classrooms in combination with online learning. The government has admitted that fully online classes for the long term may result in unexpected outcomes such as boredom, stress, and even a high dropout rate. The government authorities have emphasized that schools in yellow and green zones are permitted to conduct face-to-face learning if they adhere to rigorous health protocols. Nevertheless, even if it is claimed that those schools are safe, children will continue studying from home if their parents do not permit them to attend classes (Cabinet Secretariat of the Republic of Indonesia, 2020).

The publication of research on Emergency Remote Teaching (ERT) in foreign languages and second languages has quite recently started to arise. A preliminary review of the existing literature indicates that a growing number of studies have been carried out on ERT practices in foreign and second language education, using various data collection tools with different stakeholders, including teachers, administrators, and students. The in-depth investigation of students' voices is essential since the policy should be suitable for the subjects' needs, and preferences.

This paper is expected to fill the gap and focus on two problem formulations: the relationship between students' preference for online-blended learning and their reasons to stay safe during the pandemic. How do the students view the teaching and learning process in online and blended learning during the pandemic?

\section{Literature Review}

Remote teaching is a mode of teaching delivery that allows students to learn from physical buildings through online platforms (Riggs, 2020). Remote teaching offers positive opportunities for students to improve their knowledge and skills. First, online learning is an innovative learning model that most students have never experienced before (Agung, Surtikanti \& Quinones, 2020). Second, students have more time to do their tasks and assignments (Evisen, Akyilmaz \& Torun, 2020). The students are taught to become self-directed learners and take responsibility for their learning progress (Maison, Kurniawan, \& Anggraini, 2021). Third, students learning at home feel safe from the spread of COVID-19 (Evisen, Akyilmaz \& Torun, 2020). Remote teaching in the context of a pandemic is an emergency education approach (Bozkurt et al., 2020). Education has shifted to remote teaching due to the threat of COVID-19.

Looking back, the results of research on the integration of technology into learning are pertinent since remote teaching using online tools has been the only available alternative to address the pandemic. For example, Maison, Kurniawan, and Anggraini, (2021) suggest that technology enables teachers to provide their students with opportunities to navigate digital platforms that excel in rapid knowledge transfer. In addition, students also gain digital literacy skills and boost their self-learning development (Boelens, De Wever \& Voet, 2017; Dziuban et al., 2018). Technology offers other benefits to education because of its flexibility in implementation (Simpson, 2018; Jung, 2019; Bozkurt, 2019; Bozkurt \& Sharma, 2020; Mohammed et al., 2020). Maison, Kurniawan, and Anggraini (2021) also add that students can access materials wherever they are and whenever they want, and that they can study at their own pace.

Nevertheless, problems in remote teaching have also appeared. For example, Alim et al. (2019), Agung et al. (2020), and Pokhre and Chhetri (2021) have reported challenges such as unstable internet connectivity and the lack of networking technology support. Lynch (2020) has added that most students have severe problems sending their tasks or learning content when their internet connection is poor. Another challenge includes technical issues such as electricity blackouts due to floods, etc. (Sari, 2016; Alvarez, 2020; Mohmmed et al., 2020; Agung, Surtikanti \& Quinones, 2020; Maison, Kurniawan, \& Anggraini, 2021). Rosyada and Sundari (2021) add that students do not have equal digital literacy and technology support, especially in remote areas. These problems hamper learning quality. 
The pro and con arguments regarding online-offline teaching modes are ubiquitous. The supporters of online teaching perceive safety as the top priority. Meanwhile, the con supporters believe in effectiveness and local variations because different institutions have different circumstances and preferences (Rosyada \& Sundari, 2021). The government and educational institutions continue their pros and cons arguments in mass media to convince public opinion that their reasons are more logical and applicable. However, educational institutions hardly touch students' feelings, opinions, preferences, and reasons, and students can become the victims of policy implementation, being directly impacted by current teaching mode policies. Coeckelberg (2020) has emphasized that if we never learn from the main problem and mistakes during the COVID-19 tragedy, they will get their revenge when it is over.

\section{Method}

\subsection{Study Setting}

This research design is a survey study in which data collection techniques were carried out via a link to an online Microsoft form during a period from March to May. This questionnaire contained several questions that point to respondents' views about the barriers and benefits of being fully online, their willingness to participate in offline meetings, and parents' views about face-to-face meetings during the pandemic. In addition to seeking research results, the authors deliberately prepared this questionnaire to meet requests from university leaders to get references in making decisions about the implementation of the teaching and learning in the new semester in 2021-2022.

\subsection{Data Collection Procedure}

Gathering the responses from students is not always easy during a pandemic. Knowing that they are not always active in checking their emails, the authors used numerous ways to contact them. For example, the writers asked the faculty secretary to send survey invitations to the students through the groups of instant messengers. In addition to sending the emails, the faculty secretary managed to reach students through their social media accounts such as Instagram and Facebook. The writers received responses from sixty respondents (60), or about $32 \%$ of the whole student population studying at the faculty. Of these sixty respondents, twenty-eight (28) belonged to the Mandarin education study program and the other thirty-two (32) students from the English Letters study program. Concerning their gender, $14.3 \%$ and $85.7 \%$ are males and female students, respectively.

The questionnaire consisted of two parts. The first part dealt with demographic information such as gender, study program, and batch. The second part consisted of the following questions:

1. What kinds of obstacles did students face during the remote teaching class in the last semester?

2. Which teaching delivery models do they prefer in the coming semester? Were they entirely online or blended learning?

3. Why do they prefer complete online or blended learning?

4. What do they expect from the university if they prefer completely online or blended learning?

5. Are they willing to follow health protocols (wearing masks, sitting in spaced seats, avoiding crowds, going home after the class) when attending face-to-face meetings?

6. Are they willing to accept sanctions (reprimands) if they violate the rules?

7. Do their parents permit them to attend face-to-face activities?

8. If yes, are they willing to submit permission letters to the faculty?

The researchers carried out a face validity test by consulting with two psychometric experts. They also tested the online questionnaire by distributing it to a group of students, and they concluded that all questions met standards of readability.

\subsection{Data Analysis}

The number of samples in this study was $32 \%$ of the total population and was sufficient to represent the data distribution. The researchers estimated some parameters such as mean, median, and standard deviation to show the central data tendency. Furthermore, the Chi-square test and cross-tabulation were also used as data analysis tools. A cross-tabulation tool was employed to identify the patterns, trends, and correlation between study parameters. These also helped the authors to interpret data by drawing comparisons and correlations. 


\section{Findings and Discussions}

\subsection{Students' Preference for Full Online to Blended Learning}

This study aimed to find out whether students' preference for fully online-blended learning is related to their reasons for staying safe during the pandemic. To do so, researchers conducted a Chi-Square test to examine the alternative hypothesis; namely, students' preference for online-blended learning is related to their reasons to stay safe during the pandemic. From the SPPS calculation results, this study found the value of Asymp. Sig (2-sided) on the Pearson Chi-Square test is 0.028 , which is smaller than 0.05 . This result means that the null hypothesis should be rejected. Thus, students' preference for fully online-blended learning is significantly correlated with their reasons to stay safe during the pandemic. This also indicates that the stronger the students perceive the potential dangers of COVID-19 transmission, the more likely they are to choose a fully online class.

Table 1. Chi-Square Tests

\begin{tabular}{|c|c|c|c|}
\hline & Value & Df & $\begin{array}{c}\text { Asymptotic } \\
\text { Significance } \\
\text { (2-sided) }\end{array}$ \\
\hline Pearson Chi-Square & $9.084^{\mathrm{a}}$ & 3 & .028 \\
\hline Likelihood Ratio & 5.859 & 3 & .119 \\
\hline Linear-by-Linear Association & .110 & 1 & .741 \\
\hline $\mathrm{N}$ of Valid Cases & 60 & & \\
\hline
\end{tabular}

Most respondents (89.3\%) or about fifty-four students (54) were found to prefer a fully online class to blended learning (see Table 2). The preference of the majority of respondents was strongly affected by social agents such as their parents and social media.

The students tended to view the pandemic as dangerous, threatening health, and dramatically affecting their view of remote teaching. Most of them admitted that their parents were central figures who played an essential role in making decisions. From the perspective of the students' parents, good health was much more important than face-to-face classes. The student's parents thought that remote teaching has numerous weaknesses; for example, they were doubtful about the quality of remote teaching and were prepared to buy internet quotas and reliable electronic gadgets.

Nevertheless, fully online classes also provided benefits for both parents and students. They felt safe from the crowds and thus kept themselves healthy at home while attending online classes. In addition, the students' parents admitted that they could save money on their children's boarding room fees, transportation, and living expenses.

The parents' concerns might not be greater than those of the Chinese students' parents in Zhang's study (2021). When surveying 741 parents whose children were still studying at K-12, Zhang (2021) found that parents were overwhelmed with the potential loss of education in China. They thought that remote teaching was low quality and did not enable children to achieve essential competencies that they needed in real life. According to the parents, teachers could not control their children's learning progress during online classes, and the parents were forced to take the role of teachers for their children at home. They complained about their inability to teach and their difficulties in allocating time to meet their family needs.

In contrast, the students in the present study were in university. Their parents viewed their children as independently managing their learning. Based on this present study and Zhang's findings, we concluded that the level of education of children significantly impacts parents' view of the urgency and quality of remote teaching. The higher the level of education a child has, the more parents believe their child will be independent in regulating their learning rhythm, and thus they positively valued the quality of online classes.

Table 2. Teaching mode preference during the pandemic

\begin{tabular}{|c|c|c|c|c|c|}
\hline & & Frequency & Percent & Valid Percent & $\begin{array}{c}\text { Cumulative } \\
\text { Percent }\end{array}$ \\
\hline \multirow[t]{3}{*}{ Valid } & Full Online & 54 & 89.3 & 89.3 & 89.3 \\
\hline & Blended learning & 6 & 10.7 & 10.7 & 100.0 \\
\hline & Total & 60 & 100.0 & 100.0 & \\
\hline
\end{tabular}


Social media influenced the students' views of the pandemic. The pandemic that kept community members from having direct interactions made social media an alternative effective communication tool; people could communicate with each other while getting the latest news about conditions around the globe. According to the respondents, their lecturers employed social media such as Instagram as a medium for learning. For example, they set tasks requiring students to collect information from social media for research data. Respondents admitted that the news they obtained from social media influenced their view of the pandemic. The respondents had different reactions to the numerous news of COVID-19, and some of them have been overwhelmed with anxiety.

Meanwhile, some others were less anxious because they used the governments' official information to check the truthfulness of the news. Nevertheless, the respondents in this present study ended up having online learning regardless of the influence of social media. In the same way, Li et al. (2020) discovered how social media had a substantial impact on psychological health. Misunderstanding of news from social media could create excessive anxiety and lead to excessively avoidant behaviors. Moreover, Li et al. (2020) found that students who spent long periods on the internet were more likely to be misguided and were more likely to have experiences that triggered symptoms of anxiety. However, students experienced less anxiety if they thought that mainstream information was more trustworthy. Mora-Rodríguez and Melero-López (2021) confirmed the influence of social media on readers' perceptions. When surveying 2,034 people in Spain, they found that the more people are exposed to various kinds of news about the dangers of the COVID-19, the more likely they were to have a negative perception of COVID- 19. Fake news about COVID- 19 was quite prevalent in Spain, causing anxiety and hampering the response to the outbreak.

\subsection{Students' Perception of Fully Online and Possible Blended Learning Classes}

Furthermore, this study tried to answer the second question, namely, how students viewed the teaching and learning process in online and blended learning classes during the pandemic. This study found that the reliability of the Internet connection was the most significant problem (37.7\%) during remote teaching. Some respondents admitted that they could not afford adequate internet access because they lived in remote areas. To get better internet access, they rode on motorcycles to the internet cafe in the town. For male students, staying in an internet cafe until late at night was not a big problem. However, that is not the case for female students, who generally preferred to work on assignments until 17.00. Furthermore, heavy rainfall had a big impact on the stability of internet connections and, worst of all, often resulted in electricity blackouts. Officials from the state electricity company confirmed that they use electricity blackouts as precautions to prevent the potential danger of fallen trees or electric substations submerged by the flooding rivers (Sari, 2016).

Lynch (2020) has said that poor internet connections have been quite prevalent during the pandemic. Internet connections are a precondition for sending content remotely, but unequal access is ubiquitous, affecting both online learners and instructors. Lynch (2020) continues that twenty-seven percent of rural Americans commonly have difficulty with broadband access at a minimum speed for supporting multiple streams within a household and for consistently receiving high-quality voice, data, graphics, and video. Mahyoob (2020), teaching English to 184 English language learners in Saudi Arabia, found that students also experienced technical challenges during remote teaching. As a result, students had a strong tendency to become dissatisfied because they were unable to achieve the curriculum competencies of the class. The researchers of Lynch (2020) and Mahyoob (2020) suggest that inadequate internet access is a global phenomenon that has interfered with remote teaching even in modern countries. In addition to adjusting to more explicit teaching materials and encouraging students to engage in learning, educators need to become more tolerant of students in different circumstances. They need to consider alternative solutions to internet connection problems. For example, teachers might use low technology such as instant messengers to interact with students. Teachers might also extend the due date for assignment submissions to motivate the students who have difficulties gaining internet access.

Table 3. Challenges during online class

\begin{tabular}{llcccc}
\hline & & & & Cumulative \\
& & Frequency & Percent & Valid Percent & Percent \\
\hline Valid & Internet connection & 21 & 35.7 & 35.7 & 35.7 \\
& Task overload & 11 & 17.9 & 17.9 & 53.6 \\
& Electronic gadgets & 11 & 17.9 & 17.9 & 71.4 \\
& Electricity & 9 & 14.3 & 14.3 & 85.7 \\
& Home environment & 9 & 14.3 & 14.3 & 100.0 \\
\cline { 2 - 5 } & Total & 60 & 100.0 & 100.0 & \\
\hline
\end{tabular}


The home environment can also affect the quality of students' learning. When all family members live at home, family members often do physical activities such as cleaning the house, working in the garden, or even sports. The routine family activities of respondents, whose houses are relatively small, interfered with their online learning. For example, they had to listen carefully to lecturers' explanations during teleconferences while listening to other sounds from inside the house. Other respondents reported that they had to help younger siblings with homework. Their parents were busy doing their jobs from the office or running their businesses. As a result, the parents left the responsibility for guiding the young siblings to the respondents. Majumdar, Biswas, and Sahu (2020) and Kapasia et al. (2020) also examined the effects of home confinement and restricted access on student learning quality. They found that Indian students increased their screen time during the pandemic. Home confinement and restricted access to outdoor activities reduced physical activities and increased screen exposure.

Moreover, excessive screen time harms health by severely affecting sleep patterns and sleep duration. According to Majumdar, Biswas, dan Sahu (2020), some students developed a sleep disorder due to a change from the regular schedule pre-pandemic. Confinement to home along with anxiety and stress were most likely to contribute to depression. Learning from the findings of this study, and those from Majumdar, Biswas, and Sahu (2020) and Kapasia, et al. (2020), a house environment where most students generally access remote teaching materials can adversely affect students' mental and physical health. Consequently, educators must appropriately anticipate the increase in excessive screen time and the potential for sleep disorders so that their students can stay healthy. In addition, collaborating with parents and communicating with students about effective learning strategies can help overcome problems during online classes.

As shown in Table 2, the tendency to attend remote teaching is greater than to attend face-to-face classes. Although the Indonesian government, through the Ministry of Education and Culture, has recently granted universities or other educational units the right to carry out face-to-face education provided that it meets health protocol standards, the respondents regard the current situation as not conducive to blended learning. Moreover, current news from social media or online newspapers about the risk of COVID- 19 transmission was so powerful that it influenced the students' views and resulted in decisions to continue remote teaching. They admitted that the barriers to online classrooms were inevitable and that health is more important. Their parents played an important role in making choices regardless of the students' personal choices. They thought that the current conditions were not safe for their children to participate in a face-to-face meeting. Learning could happen although it was done online. Moreover, they believed that their children, as college students, should be independent and should take responsibility for managing their learning. For the parents, online learning offered their children the flexibility to access materials anytime and anywhere. They no longer spent money for house rent, transportation, food, and beverage as they had done before the pandemic.

Only six parents responded that they allowed their children to attend face-to-face classes (see Table 5). They argued that face-to-face classes were much better for promoting promote quality learning. They thought it was difficult to control their children's learning progress via remote teaching. Moreover, these parents pitied their children because of the current home confinement during the pandemic.

However, both types of parents had something in common. They urged the university to be willing to discount tuition fees. Their requests were forwarded to university leaders due to their difficult economic circumstances during the pandemic. After a series of discussions, the university leaders come up with a financial relaxation policy, allowing the parents to take a more extended payment schedule for tuition.

Table 4. Reasons for choosing an online class

\begin{tabular}{llcccc}
\hline & & & & \multicolumn{2}{c}{ Cumulative } \\
& & Frequency & Percent & Valid Percent & Percent \\
\hline Valid & Safety & 45 & 75.0 & 75.0 & 75.0 \\
& Low costs & 2 & 3.6 & 3.6 & 78.6 \\
& No permission from parents & 11 & 17.9 & 17.9 & 96.4 \\
& Taking care of a sick person & 2 & 3.6 & 3.6 & 100.0 \\
\cline { 2 - 6 } & Total & 60 & 100.0 & 100.0 & \\
\cline { 2 - 6 }
\end{tabular}

Based on the results of the cross-tabulation analysis in Table 5, we can identify the characteristics of two groups of respondents: the respondent group who chose the online class and the respondent group who chose the blended learning. The characteristics of the online group were those who had internet connection problems. They considered 
full online classes to be an overloaded task, with problems in technology and electricity supply, and they felt uncomfortable with the home environment. However, surprisingly enough, they were so tolerant of these problems that they still preferred fully online classes.

Table 5. The result of cross-tabulation between challenges and teaching mode

\begin{tabular}{llc|c|c}
\hline & & \multicolumn{2}{c}{ Teaching mode preference } & \\
\cline { 3 - 4 } & & online & $\begin{array}{c}\text { Blended } \\
\text { learning }\end{array}$ & Total \\
\hline \multirow{2}{*}{ Challenges } & Internet connection & 21 & 0 & 21 \\
\cline { 2 - 4 } & Task overload & 11 & 0 & 11 \\
\cline { 2 - 4 } & Electronic gadgets & 11 & 0 & 11 \\
\cline { 2 - 4 } & Electricity & 9 & 0 & 9 \\
\cline { 2 - 4 } & Home environment & 2 & 6 & 60 \\
\hline Total & & 54 & 6 & 60 \\
\hline
\end{tabular}

The findings of this study confirmed that all parties have become increasingly dependent on technology due to the pandemic. They have no choice but to accept that the integration of technology into learning should be seen as an opportunity to improve the quality of learning, regardless of the pandemic. Will full remote teaching positively impact students' language skills and language proficiency? Our literature review shows that the relationship is highly conditional and varied. However, Akbana, Rathert, and Aqcam (2021) emphasize that remote teaching has taught our students good lessons; they are taught to embrace self-directed learning, become digitally literate, get engaged in learning activities, adopt problem-solving skills, and become autonomous learners. In addition, ERT has favored disabled students who are not required to perform an excessive physical movement in learning.

\section{Conclusions}

Remote teaching might not be perfect, but it offers the best of available alternatives amid the pandemic. Unfortunately, many views of remote teaching practices are pessimistic. For example, remote teaching misses the interactions full of social and emotional messages shared by teachers and students in most conventional classrooms. Viewed as self-paced learning that encourages the students to learn independently, an online class is likely to widen the gap between teachers and students and could overwhelm students with feelings of alienation. Sadly, numerous teachers often leave the students confused because they only send teaching materials to students without any explanation or feedback. Educators can be very pessimistic about online education because the quality learning of online classes is hardly monitored and measured. These factors tend to compel both the government and many educators to finally open face-to-face classes amid the pandemic.

This study found that students' perception of unsafe face-to-face meetings during the pandemic influences their preference to study online. Compared to the risk of contracting COVID-19 transmission, they appeared to be very tolerant of numerous hindrances in remote teaching such as internet constraints, task overload, interference from other activities in the home environment, and electricity problems. Moreover, many educators feel that online classes cannot meet all the expectations of a quality learning process, such as difficulties in monitoring students in learning, and not fulfilling specific skills that require guidance and interaction. The fear of transmission from COVID- 19 is the biggest obstacle that prevents face-to-face classes from running. An awareness of the dangers of COVID- 19 is indeed a good characteristic, but it is also true that excessive fear makes people overreact.

Will this pandemic make all learning activities fully and permanently online? The fact is that the pandemic has "introduced" a new learning civilization. The educators must innovate in designing and implementing learning strategies and methods. They are forced to discard old habits and outdated teaching traditions. They become connected with global learning communities and educational institutions, giving them opportunities to collaborate with people from all over the world and to learn from them. Online learning can reach students in remote areas of the country at a low cost. This strongly supports the fulfilment of the ideals of the equal distribution of education to all people at all levels of society. Furthermore, if online learning is developed and managed correctly, it introduces the concept of "learning without borders." Education is accessible to all levels of society in all corners of the country without boundaries of location, race, ethnicity, religion, class, or time.

\section{References}

Adhikari, S. P., Meng, S., Wu, Y., Mao, Y., Ye, R., Wang, Q., .. Zhou, H. (2020). Epidemiology, causes, clinical 
manifestation and diagnosis, prevention, and control of coronavirus disease (COVID-19) during the early outbreak period: a scoping review, Infectious Diseases of Poverty, 9(1), 1-12. https://doi.org/10.1186/s40249-020-00646-x

Agung, A. S. N., Surtikanti, M. W., \& Quinones, C. A. (2020). Students' perception of online learning during COVID-19 Pandemic: A case study on the English students of STKIP Pamane Talino. SOSHUM: Jurnal Sosial Dan Humaniora, 10(2), 225-235. https://doi.org/10.31940/soshum.v10i2.1316

Akbana, Y. E., Rathert, S., \& Ağçam, R. (2021). Emergency remote education in foreign and second language teaching. Turkish Journal of Education, 10(2), 97-124. https://doi.org/10.19128/turje.865344

Alim, N., Linda, W., Gunawan, F., \& Saad, M. S. M. (2019). The effectiveness of Google classroom as an instructional media: A case of State Islamic Institute of Kendari, Indonesia. Humanities and Social Sciences Reviews, 7(2), 240-246. https://doi.org/10.18510/hssr.2019.7227

Alvarez, A. J. (2020). The phenomenon of learning at a distance through emergency remote teaching amidst the pandemic crisis. Asian Journal of Distance Education, 15(1), 144-153. https://doi.org/10.5281/zenodo.3881529

Anderson, T. (2008). The theory and practice of online learning. Oxford: Athabasca University Press. Retrieved from https://auspace.athabascau.ca/bitstream/handle/2149/411/?sequence $=1$

Boelens, R., De Wever, B., \& Voet, M. (2017). Four key challenges to the design of blended learning: A systematic literature review. Educational Research Review, 22(1), 1-18. https://doi.org/10.1016/j.edurev.2017.06.001

Bozkurt, A. (2019). From distance education to open and distance learning: A holistic evaluation of history, definitions, and theories. In Handbook of Research on Learning in the Age of Transhumanism (252-273). IGI Global. https://doi.org/10.4018/978-1-5225-8431-5.ch016

Bozkurt, A., \& Sharma, R. C. (2020). Emergency remote teaching in a time of global crisis due to Corona Virus pandemic. Asian Journal of Distance Education, 15(1), 1-6. https://doi.org/10.5281/zenodo.3778083

Bozkurt, A., Jung, I., Xiao, J., Vladimirschi, V., Schuwer, R., Egorov, G., ... Paskevicius, M. (2020). A global outlook to the interruption of education due to COVID-19 pandemic: Navigating in a time of uncertainty and crisis. Asian Journal of Distance Education, 15(1), 1-126. Retrieved from https://asianjde.org/ojs/index.php/AsianJDE/article/view/462

Cabinet Secretariat of the Republic of Indonesia. (2020). Face-to-Face Learning Need Permission from Regional Gov't, Parents. Retrieved May 10, 2021, from

https://setkab.go.id/en/face-to-face-learning-need-permission-from-regional-govt-parents/

Coeckelbergh, M. (2020). The post-digital in pandemic times: A comment on the Covid-19 crisis and its political epistemologies. Postdigital Science and Education, 2(1), 1-4. https://doi.org/10.1007/s42438-020-00119-2

Daniel, S. J. (2020). Education and the COVID-19 pandemic. Prospect, 49(1), 91-96. https://doi.org/10.1007/s11125-020-09464-3

Dhawan, S. (2020). Online learning: A panacea in the time of COVID-19 crises. Journal of Educational Technology, 49(1), 5-22. https://doi.org/10.1177/0047239520934018

Dziuban, C., Graham, C. R., Moskal, P. D., Norberg, A., \& Sicilia, N. (2018). Blended learning: the new normal and emerging technologies. International Journal of Educational Technology in Higher Education, 15(1), 3-16. https://doi.org/10.1186/s41239-017-0087-5

Elhawwa, T. (2017). The implementation of Moodle platform through the lecturer's perspectives at the English department. Journal on English as a Foreign Language, 7(2), 227-240. https://doi.org/10.23971/jefl.v7i2.502

Evisen, N., Akyilmaz, Ö., \& Torun, Y. (2020). A case study of University EFL preparatory class students' attitudes towards online learning during COVID--19 in Turkey. Gaziantep Üniversitesi Eğitim Bilimleri Dergisi, 4(2), 73-93. Retrieved June 9, 2021, from https://dergipark.org.tr/en/pub/guebd/issue/59201/803017

Handarini, O. I., \& Wulandari, S. S. (2020). Pembelajaran daring sebagai upaya study from home (SFH) selama pandemi COVID- 19 [Online learning as a study from home (SFH) effort during the COVID- 19 pandemic]. Jurnal Pendidikan Administrasi Perkantoran (JPAP), 8(3), 496-503. Retrieved from https://journal.unesa.ac.id/index.php/jpap/article/view/8503/4094

Horzum, M. B. (2017). Interaction, structure, social presence, and satisfaction in online learning. Eurasia Journal of Mathematics, Science and Technology Education, 11(3), 505-512. https://doi.org/10.12973/eurasia.2014.1324a 
Jung, I. (2019). Introduction to theories of open and distance education. In Jung I. (Eds.), Open and Distance Education Theory Revisited. Singapore: Springer. https://doi.org/10.1007 /978-981-13-7740-2_1

Kapasia, N., Paul, P., Roy, A., Saha, J., Zaveri, A., Mallick, M., ... Chouhan, P. (2020). Impact of lockdown on learning status of undergraduate and postgraduate students during COVID-19 pandemic in West Bengal, India. Children and Youth Services Review, 116(1), 25-45. https://doi.org/10.1016/j.childyouth.2020.105194

Li, M., Liu, L., Yang, Y., Wang, Y., Yang, X., \& Wu, H. (2020). The psychological impact of health risk communication and social media on college students during the COVID-19 pandemic: Cross-sectional study. Advancing Digital Health and Open Science, 22(11), 1-13. https://doi.org/10.2196/20656

Lynch, M. (2020). E-Learning during a global pandemic. Asian Journal of Distance Education, 15(1), 189-195. https://doi.org/10.5281/zenodo.3881785

Mahyoob, M. (2020). Challenges of e-learning during the COVID-19 pandemic experienced by EFL Learners. Arab World English Journal, 11(4), 351-362. https://doi.org/10.24093/awej/vol11no4.23

Maison, M., Kurniawan, D. A., \& Anggraini, L. (2021). Perception, attitude, and student awareness in working on online tasks during the COVID--19 pandemics. Indonesian Journal of Science Education, 9(1), 108-118. https://doi.org/10.24815/jpsi.v9i1.18039

Majumdar, P., Biswas, A., \& Sahu, S. (2020). COVID-19 pandemic and lockdown: cause of sleep disruption, depression, somatic pain, and increased screen exposure of office workers and students of India. Chronobiology International, 37(8), 1191-1200. https://doi.org/10.1080/07420528.2020.1786107

Mohmmed, A. O., Khidhir, B. A., Nazeer, A., \& Vijayan, V. J. (2020). Emergency remote teaching during Coronavirus pandemic: the current trend and future directive at Middle East College Oman. Innovative Infrastructure Solutions, 5(72), 1-11. https://doi.org/10.1007/s41062-020-00326-7

Mora-Rodríguez, A., \& Melero-López, I. (2021). News consumption and risk perception of COVID-19 in Spain. Comunicar: Media Education Research Journal, 29(66), 67-77. https://doi.org/10.3916/C66-2021-06

Pokhre, S., \& Chhetri, R. (2021). A literature review on the impact of COVID-19 pandemic on teaching and learning. SAGE Journal, 8(1), 133-141. https://doi.org/10.1177\%2F2347631120983481

Riggs, S. (2020, April 15). Student-centered remote teaching: Lessons learned from online education. EDUCAUSE Review. Retrieved May 14, 2021, from https://er.educause.edu/blogs/2020/4/student-centered-remote-teaching-lessons-learned-from-online-education

Rosyada, A., \& Sundari, H. (2021). Learning from the home environment: Academic writing course for EFL undergraduates through Google classroom application. Studies in English Language and Education (SIELE), 8(2), 710-725. https://doi.org/10.24815/siele.v8i2.18374

Sari, N. I. (2016, November 13). Ini jawaban PLN sering ada mati lampu saat musim hujan. Retrieved May 18, 2021, from https://www.merdeka.com/uang/ini-jawaban-pln-sering-ada-mati-lampu-saat-musim-hujan.html

Simpson, O. (2018). Supporting students in online, open, and distance learning. London: Routledge. https://doi.org/10.4324/9780203417003

Sulisworo, D., Fatimah, N., Sunaryati, S. S., \& Sanidi. (2020). A quick study on SRL profiles of online learning participants during the anticipation of the spread of COVID-19, International Journal of Evaluation and Research in Education (IJERE), 9(3), 723-730. https://doi.org/10.11591/ijere.v9i3.20642

Yundayani, A., Susilawati, \& Chairunnisa. (2019). Investigating the effect of Canva on students' writing skills. English Review: Journal of English Education, 7(2), 169-176. https://doi.org/10.25134/erjee.v7i2.1800

Zhang, T. (2021). Chinese parents' perception of emergency remote K-12 teaching-learning in China during the COVID-19 pandemic. Asian Journal of Distance Education, 16(1), 16-30. https://doi.org/10.5281/zenodo.4567480

\section{Copyrights}

Copyright for this article is retained by the author(s), with first publication rights granted to the journal.

This is an open-access article distributed under the terms and conditions of the Creative Commons Attribution license (http://creativecommons.org/licenses/by/4.0/). 